\title{
HPV knowledge and vaccine acceptance among European adolescents and their parents: a systematic literature review
}

Noelia López ${ }^{1 *}$, Maria Garcés-Sánchez ${ }^{2}$, Maria Belén Panizo ${ }^{3}$, Ignacio Salamanca de la Cueva ${ }^{4}$, Maria Teresa Artés ${ }^{5}$, Beatriz Ramos ${ }^{1}$ and Manuel Cotarelo ${ }^{1}$

* Correspondence: noelia.lopez@ merck.com

${ }^{1}$ Medical Affairs Department, Merck Sharp \& Dohme Spain, Madrid, Spain

Full list of author information is available at the end of the article

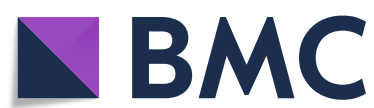

(c) The Author(s). 2020 Open Access This article is licensed under a Creative Commons Attribution 4.0 International License, which permits use, sharing, adaptation, distribution and reproduction in any medium or format, as long as you give appropriate credit to the original author(s) and the source, provide a link to the Creative Commons licence, and indicate if changes were made. The images or other third party material in this article are included in the article's Creative Commons licence, unless indicated otherwise in a credit line to the material. If material is not included in the article's Creative Commons licence and your intended use is not permitted by statutory regulation or exceeds the permitted use, you will need to obtain permission directly from the copyright holder. To view a copy of this licence, visit http://creativecommons.org/licenses/by/4.0/. The Creative Commons Public Domain Dedication waiver (http://creativecommons.org/publicdomain/zero/1.0/) applies to the data made available in this article, unless otherwise stated in a credit line to the data. 
genotypes, are responsible for $90 \%$ of genital warts [2]. Apart from anogenital cancers, HPV is known to be responsible for a variable fraction of head and neck cancers [3].

Approximately, $80 \%$ of sexually active individuals will be infected by HPV during their lifetime [4]. Most of these infections are immunologically controlled within 1-2 years. However, if the infection persists, it can cause cellular changes that can lead to certain types of cancers. According to the latest data reported for Europe, an estimated 680,344 to 844,391 genital warts; 216,636 to 413,977 cases of high-grade cervical intraepithelial lesions (CIN2+); 31,130 cervical cancer cases; 6786 head and neck cancers; and 10,076 cancers in vulva, vagina, penis, and anus attributable to the aforementioned nine HPV types [2] are diagnosed annually in males and females. Some of these conditions, such as anal or oropharyngeal cancer, have increased recently [5].

Currently, there are three licensed HPV vaccines in the European Union (EU): a bivalent, including HPV types 16 and 18, approved in 2006; a tetravalent, including HPV types 6, 11, 16, and 18, authorized in 2006; and a nonavalent vaccine, including HPV 6, $11,16,18,31,33,45,52$ and 58 that was licensed in 2015 [6-8]. According to the European Centre for Disease Prevention and Control (ECDC), by 2012, 19 European countries had introduced HPV vaccination in females, and ten of them had organized catch-up programs [9]. More recently, certain countries have extended HPV vaccination to males within their immunization programs. Up to 27 countries globally, 13 of them in Europe have implemented gender-neutral vaccination programs [10].

Despite these advances, coverage rates of HPV vaccination programs differ widely between countries [9]. To address this, in May 2017, the World Health Organization (WHO) underlined the importance of cervical cancer and other HPV-related diseases as a global public health problem and reiterated its recommendation to include HPV vaccines in national immunization programs as part of a coordinated and comprehensive strategy to prevent HPV-related diseases [11].

Since most HPV vaccination programs target mainly young adolescents, parents have the authority to take most decisions about vaccination. Therefore, the success of HPV vaccination programs will largely depend on parental decision-making [12]. A comprehensive model to explain vaccine hesitancy among parents was defined by Dubé et al. [13] including a number of factors at the individual level: knowledge and information, past experiences, perceived importance of vaccination, risk perception and trust, subjective norm, religious and moral convictions but also the historical, political, and socio-cultural context, public health policies, health professionals recommendations, and media influence.

The concept of knowledge commonly includes the awareness about "who, where, and when" one should be vaccinated and self-estimated sufficiency of information about vaccination or satisfaction with information on vaccination [13]. While acceptability is a more complex multi-faceted construct that reflects the extent to which people delivering or receiving a healthcare intervention consider it to be appropriate, based on anticipated or experienced cognitive and emotional responses to the intervention [14]. Several theoretical models of acceptability have been proposed in the literature. The $5 \mathrm{C}$ model [15] describes five relevant psychological antecedents of vaccination: confidence, complacency (risk perceptions), constraints (barriers), calculation (extent of information search), and collective responsibility (willingness to protect the community). 
Since the introduction of HPV vaccines, several studies have been conducted in different countries to assess HPV knowledge and vaccine acceptance.

At the end of 2017, two systematic reviews explored factors related to the uptake of vaccination programs in the EU $[16,17]$. The first one [16] examined worldwide HPV vaccination uptake and associated factors; however, studies not reporting HPV vaccination coverage rates were excluded. The second study [17] assessed parental attitudes toward HPV vaccination in male children; no data about female vaccination were included. Consequently, there is no comprehensive systematic literature review summarizing factors influencing HPV knowledge and vaccine acceptance among adolescents and their parents since the introduction of HPV vaccines until now in EU countries. Moreover, to our knowledge, no publication has consistently compiled measurement tools used in published studies that assessed HPV knowledge and vaccine acceptance. This compilation could be useful for new researchers in this field.

The aim of this study was to perform a systematic literature review to identify factors associated with HPV knowledge and vaccine acceptance in adolescents and their parents, to summarize the results for both outcomes, and to compile the measurement tools, items, and questionnaires used in published research studies performed in European countries where HPV vaccines are licensed.

\section{Methods}

We reviewed all the scientific literature published between January 1st, 2006 and December 31st, 2017 to identify studies evaluating parental and/or adolescent HPV knowledge and/or acceptance of HPV vaccination. Our search was limited to studies targeting populations from European countries where HPV vaccines were licensed when this protocol was written to ensure homogeneity as far as common regulation (European Medicines Agency, EMA) among the included countries and common vaccination recommendations (European Centre for Disease Prevention and Control, EDCD) (Austria, Belgium, Bulgaria, Croatia, Cyprus, Czech Republic, Denmark, Estonia, Finland, France, Germany, Greece, Hungary, Iceland, Ireland, Italy, Latvia, Liechtenstein, Lithuania, Luxemburg, Macedonia, Netherlands, Norway, Portugal, Serbia, Slovenia, Spain, Sweden, Switzerland, and the UK).

\section{Inclusion and exclusion criteria}

Studies whose primary outcomes were HPV knowledge and/or acceptance of HPV vaccination were included. Following PICOTS, we defined the following criteria for study selection:

- Population: only studies performed in parents of children of any age under 19 years or an adolescent population defined as individuals aged 9-18 years old living in a European country where HPV vaccines were licensed were included.

- Intervention: not applicable.

- Comparator: results regarding HPV knowledge and acceptability of HPV vaccination were recalled, whenever possible by sex of the respondent, sex of the target child, and country. 
- Outcomes: a study was regarded as measuring knowledge of HPV if it assessed a set of true/false, yes/no or any other format of questions that could be translated into a scoring system showing the knowledge and understanding of how the virus is spread, what conditions result from HPV infections and how HPV can be prevented. A study was regarded as measuring acceptance of HPV vaccination whenever it somehow evaluated a positive or negative intention or willingness toward vaccinating children (girls or boys) or oneself (in the case of adolescents) in the future (vaccine intention); or having consented or not to vaccination their children or oneself (in the case of adolescents) in the past. In addition, drivers for accepting HPV vaccination and barriers and reasons to refuse it were recorded and analyzed.

Study design: quantitative survey research studies published as original articles were included. Reviews, editorials, and gray literature (dissertations, conference abstracts, trial registries, pharmaceutical company databases, etc.) were not included in the search.

- Time: only studies published in English during the last 11 years were included (2006-2017).

\section{Search strategy}

The search strategy used appropriate keywords, medical subject heading, and free-text terms for the following concepts: "human papillomavirus AND [survey OR questionnaire OR assessment] AND [knowledge OR acceptance OR attitudes] AND vaccine."

A combination of text words and MeSH Terms was defined with a medical librarian and after several preliminary manual test searches.

The following principal sources of electronic reference libraries were searched to access the available data: The Cochrane Library, Medline through PubMed, EMBASE, and Popline. An exploratory search in Google and Google Scholar was also made to avoid any publication bias.

We also included the World Bank Library Network, although we did not obtain relevant publications from this source.

The list of search queries used per bibliographic source is provided in the Supplementary Material.

\section{Study selection}

The titles of all studies identified were screened independently by two reviewers and duplicates were removed. Titles were screened for inclusion and abstracts were further reviewed based on eligibility criteria. Any disagreements on selection of studies between the two primary reviewers were resolved by an expert committee comprised of four expert pediatricians in HPV and vaccination (MGS, DMP, MBO, and ISC). Following retrieval of the full texts of all the studies that met the inclusion/exclusion criteria, data confirming these criteria were extracted from each study by the two reviewers on a standardized abstraction sheet. Any disagreement on the final selection of studies to be included in the review was resolved by the expert committee. 


\section{Assessment of study quality in included studies}

Study quality was assessed by two independent reviewers using the Mixed Method Assessment Tool (MMAT) developed by Pluye et al. [18] (see Supplementary Material) to identify factors that might have introduced bias or limited the generalizability of the results. In case of non-concordance, the expert committee also assessed the quality of the non-concordant studies and a consensus decision was taken by the two reviewers and the expert committee. Studies showing a MMAT score $<50$ were excluded.

\section{Data collection}

Data extraction was performed by the lead reviewer using a bespoke form. An additional reviewer checked a random sample of $15 \%$ of the data records to detect possible extraction errors.

The form's suitability was assessed by performing a pilot extraction of three studies selected on the basis of the diversity of their content and design. Both the lead reviewer and the additional reviewer performed the pilot extraction independently. Results and completion difficulties were subsequently compared to improve the questionnaire accordingly. The final data extraction form used is included in the Supplementary Material.

\section{Data analysis}

Items were classified under headings and subheadings based on their conceptual meaning. Main headings were knowledge about HPV, knowledge about HPV vaccine, acceptability of vaccines in general, and acceptability of HPV vaccine. The complete list of subheadings defined under each heading is shown in first column of Table 2.

For each individual item reported by the studies included, the literal item text, the reported number, and percentage of participants choosing the response answer that implies knowledge (yes, true, correct...) and/or acceptability (yes, positive, agreement...), respectively was recorded in a database.

For each heading and subheading, the number of items reporting data, sum of the studies' sample size, sum of the number of participants answering each item as previously defined, computed pooled percentage (based on the two previous frequency values), arithmetic mean of the percentages of the items included in the heading, minimum reported percentage, and maximum reported percentage for each conceptual heading in the original study were obtained or calculated.

To collect the information on factors associated with HPV knowledge and/or HPV vaccine acceptance, reviewers extracted the data of odds ratio, beta coefficients, or $p$ values (depending on availability) reported in the included studies that presented a statistical association with HPV knowledge and/or with the acceptance of HPV vaccination. Total number of studies studying each factor is reported and whether the analysis of the relationship was multivariate or bivariate.

\section{Results}

A total of 2118 publications were identified: 609 were retrieved from PubMed, 206 from Cochrane Library, 1124 from EMBASE, 141 from the World Bank Library, and 38 
from Popline. The exploratory search in Google and Google Scholar did not yield any new peer-reviewed publication not already included.

Duplicates were excluded and 1666 publications were retained for title and abstractbased screening. Of these, 1516 were excluded according to selection criteria. Only 150 were selected for full-text review. Eleven of them were excluded because the aim of the study was not consistent with the objective of this systematic review, ten were not original papers providing primary data, one was conducted in a country where HPV vaccines were not commercialized, 18 did not provide segregated data for the target population of this review or were conducted in a different target population, 31 studies were performed in non-European countries, four were published in a language other than English, and three were additional duplicates.

Thus, 72 studies that met the inclusion criteria were finally included, although two had to be excluded after quality evaluation with MMAT. Ultimately, 70 publications were included for further analysis. See PRISMA flow diagram (Fig. 1), list of excluded studies and reason for exclusion in Supplementary Material.

All 70 publications were non-interventional studies, 14 were qualitative studies and were therefore not included in the quantitative synthesis, although they were used to guide the conceptual framework to classify the items of quantitative studies under headings and subheadings. Items used across studies to measure this knowledge were divided into two main headings: knowledge of HPV and knowledge of HPV vaccine. We also included a third heading for "other" information, such as knowledge of sexually transmitted infections (STI). Items related to information source were also classified (see Supplementary Material).

Thirty-eight publications reported data about HPV knowledge and 40 about HPV vaccine acceptance. Of them, 20 and 37 studies, respectively, reported quantitative results about factors influencing HPV knowledge and HPV vaccine acceptance.

In terms of geographical distribution, publications included in this review were produced in 16 European countries, the UK having most publications, 20 (28.6\%), followed by Italy, ten (14.3\%), and Sweden, eight (11.4\%). There was only one pan-European study involving four countries: France, the UK, Germany, and Italy.

Twenty-nine studies were conducted on adolescents aged between 9 and 21 years (15 in females, one in males, and 13 in both genders); 36 were conducted in parents of adolescents (12 in mothers only and 24 in in both parents). A summary of the characteristics of studies included in the systematic review is provided in Table 1.

\section{Results of studies evaluating HPV knowledge in adolescents and their parents}

Thirty-eight studies reported data results on HPV knowledge. Table 2 presents the results of each study included in this systematic review grouped by headings and subheadings. A total of 154,090 adolescents and 75,597 parents answered one or some of the items included in this review. The percentage of adolescents that had heard about HPV varied greatly in the studies; from 5.2\% [64] to 94.0\% [54]. This same applied to parents: the percentage of parents that had heard about HPV varied between 29.5\% [68] and 93.8\% [74] depending on the study.

Between 1.1\% [63] and 94.5\% [47] of adolescents and 6.2\% [68] and 93.8\% [74] of parents said they had heard of HPV vaccine. Only one study assessed HPV vaccine knowledge in boys. 


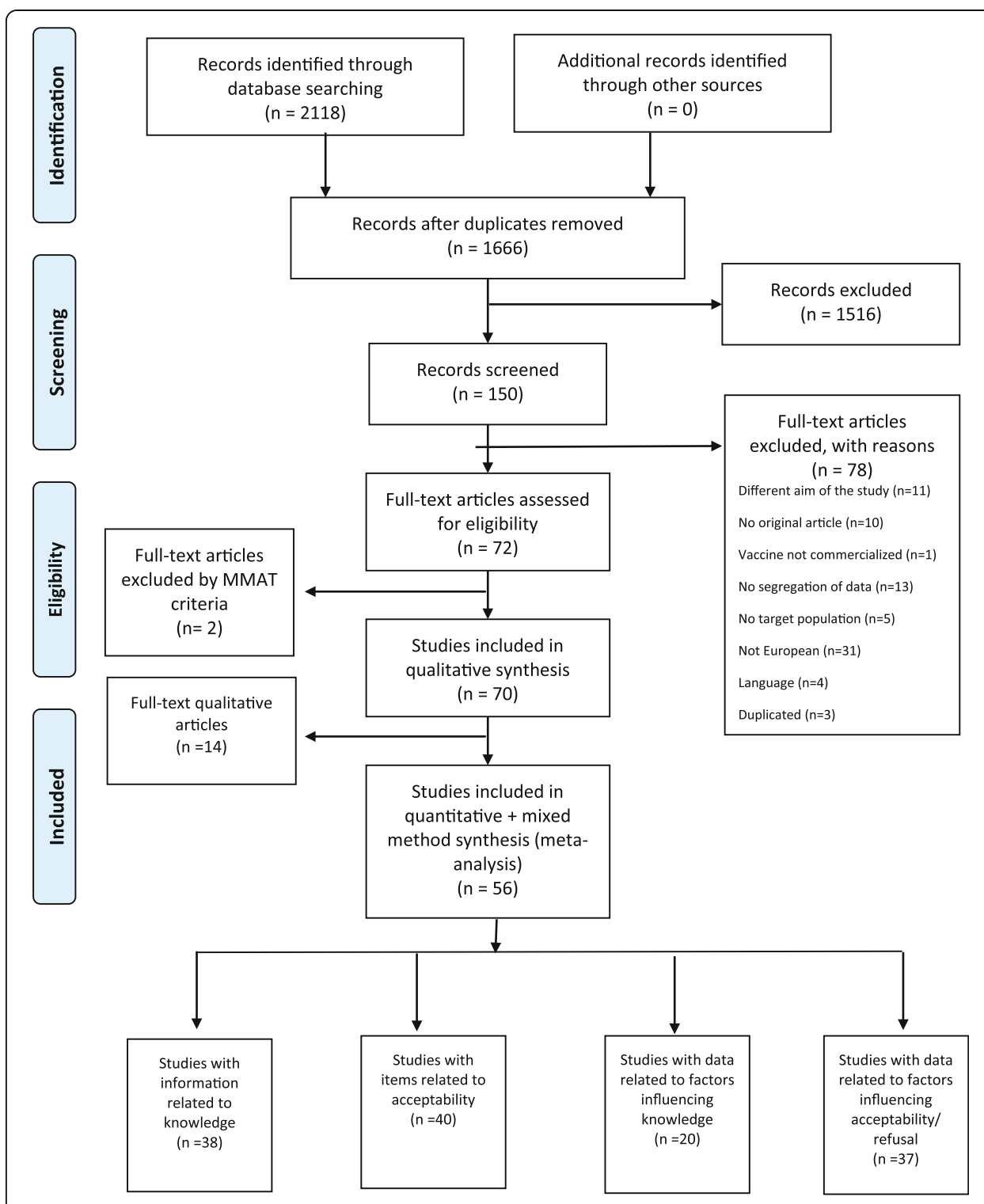

Fig. 1 PRISMA flow diagram

Studies performed in Finland were the ones showing the highest overall knowledge of HPV among parents; around 79\% of Finnish respondents answered correctly to items related to HPV knowledge, followed by studies in the UK and Germany $(72.4 \%$ and $74 \%$, respectively). The lowest percentage was in The Netherlands (37.9\%). Among adolescents, Belgium studies showed the highest percentage of HPV knowledge (93\%), followed by Italian's (66.6\%), and the lowest was in Sweden (10.9\%). HPV vaccination knowledge varied also between 6.2 and $90.6 \%$ in parents, being highest in the UK and lowest in the Netherlands studies; and between 10.1 and $87.1 \%$ in adolescents, being highest in Belgium and lowest in Latvia (Fig. 2).

Parents' most common source of information on HPV was the pediatrician, $46.9 \%$ [66] to $92 \%$ [38] of the respondents depending on the publication, whereas for adolescents it was school ranging from 0\% [36] to 61.3\% [58]. However, the most common source of information of HPV vaccines was the vaccination centre for parents (77.3\%) 


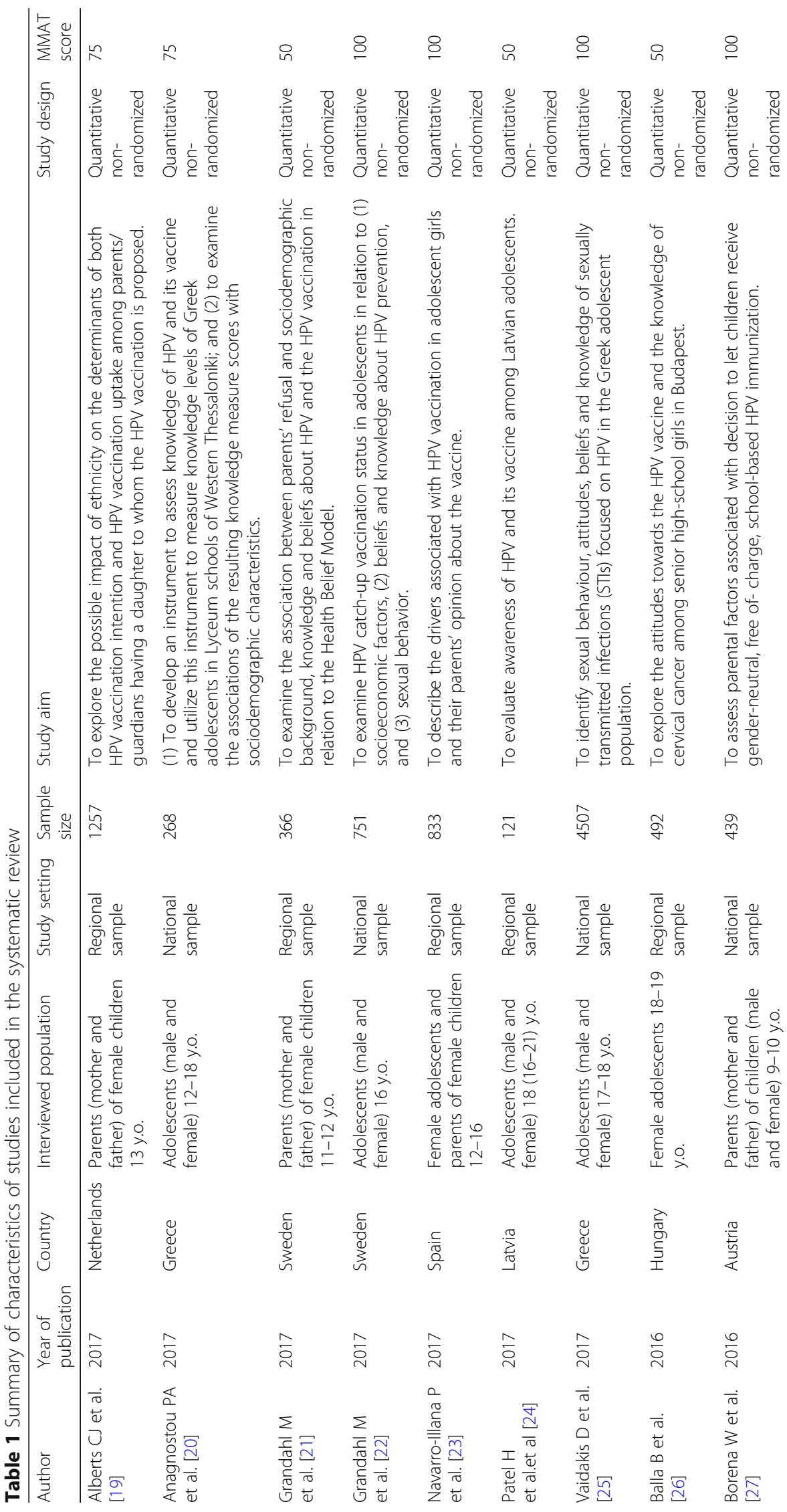




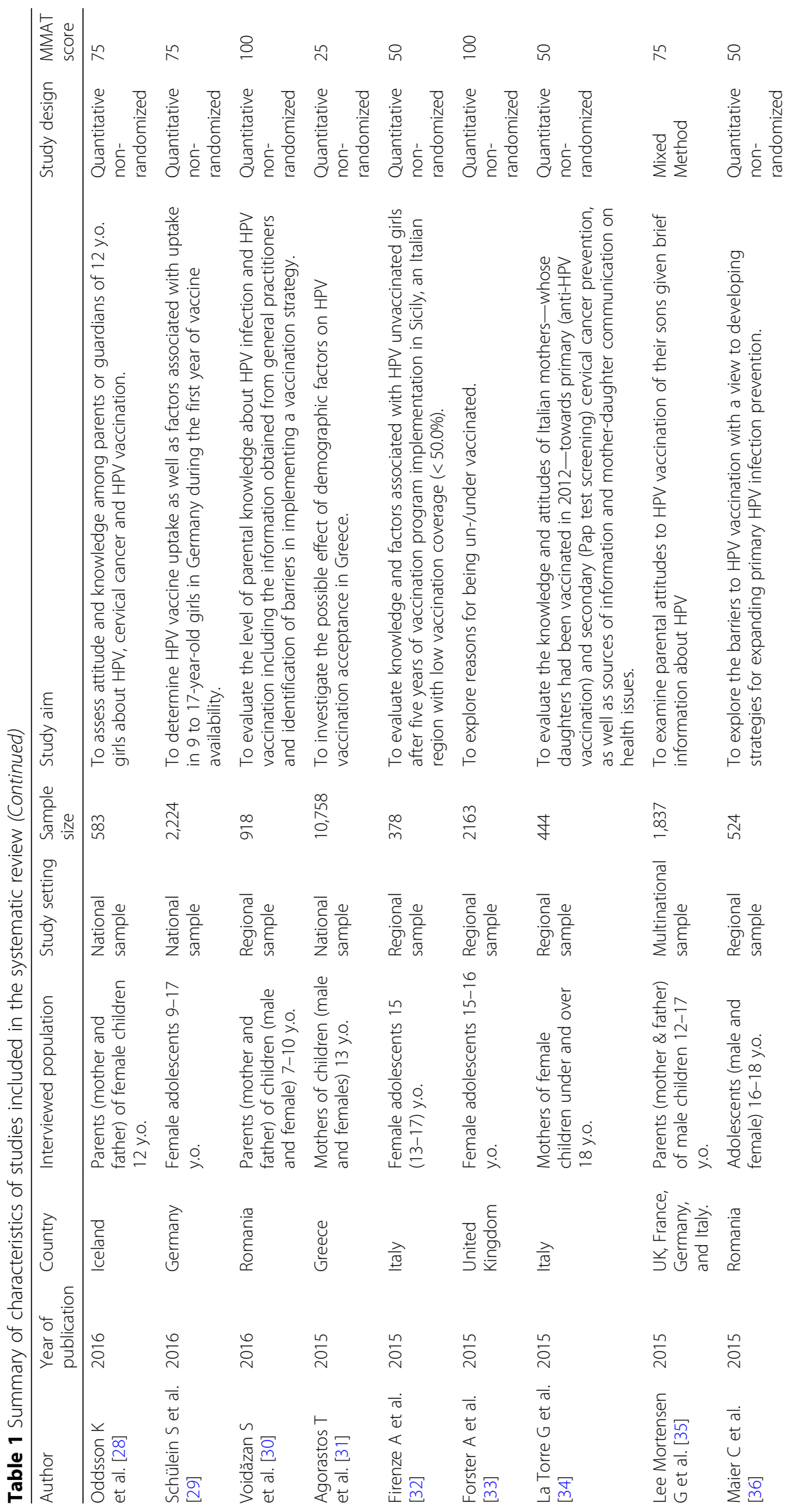




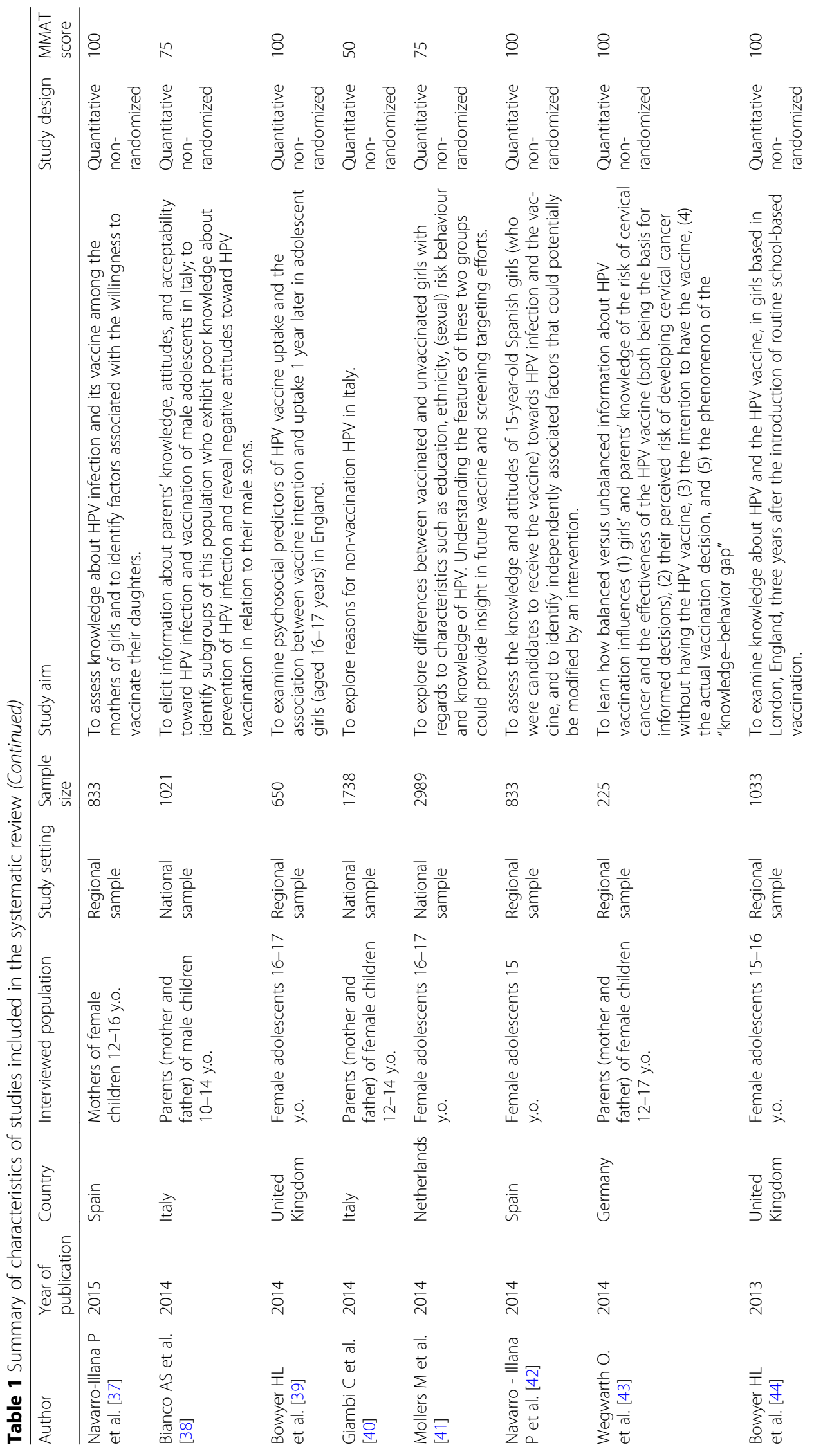




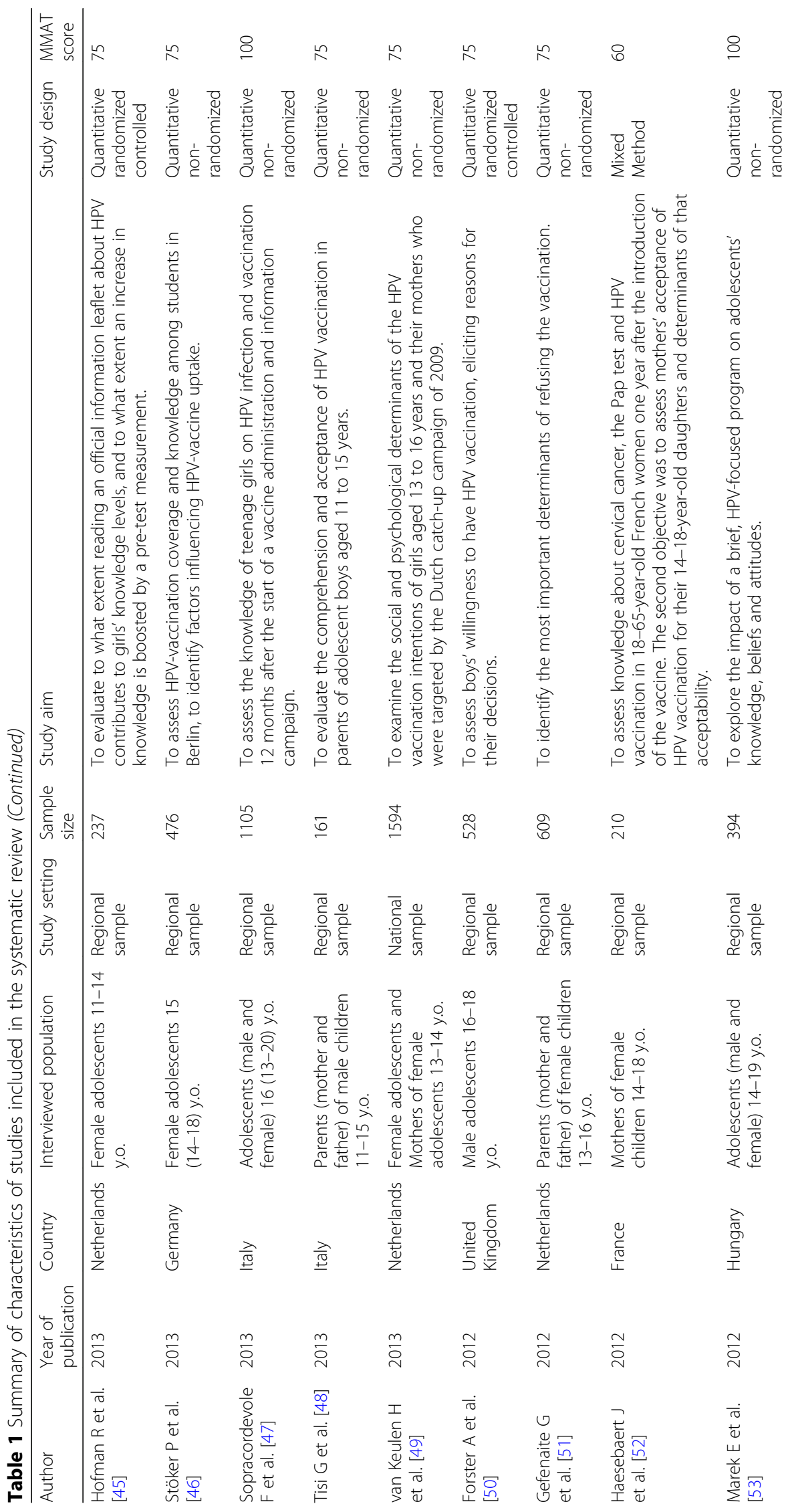




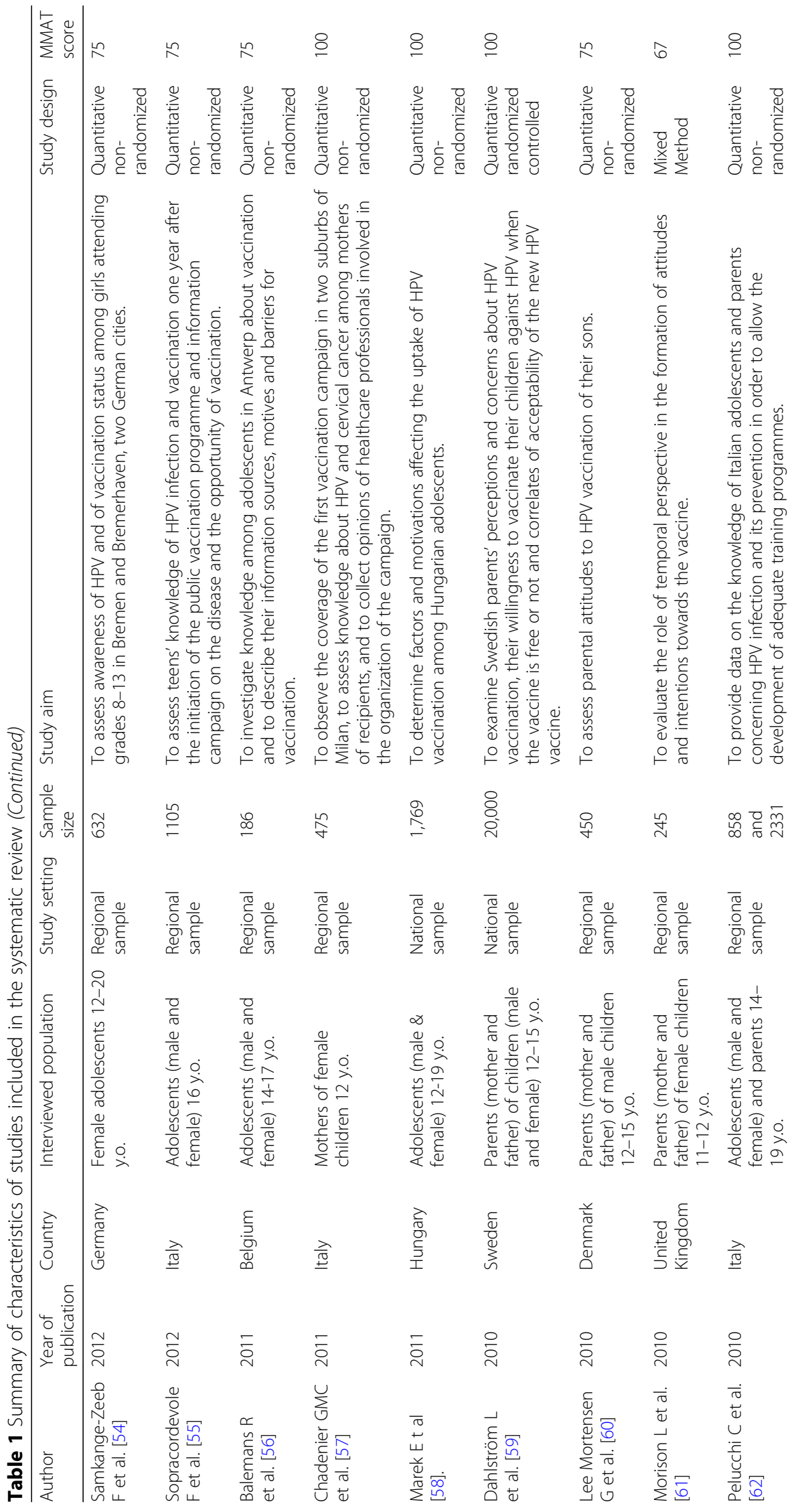




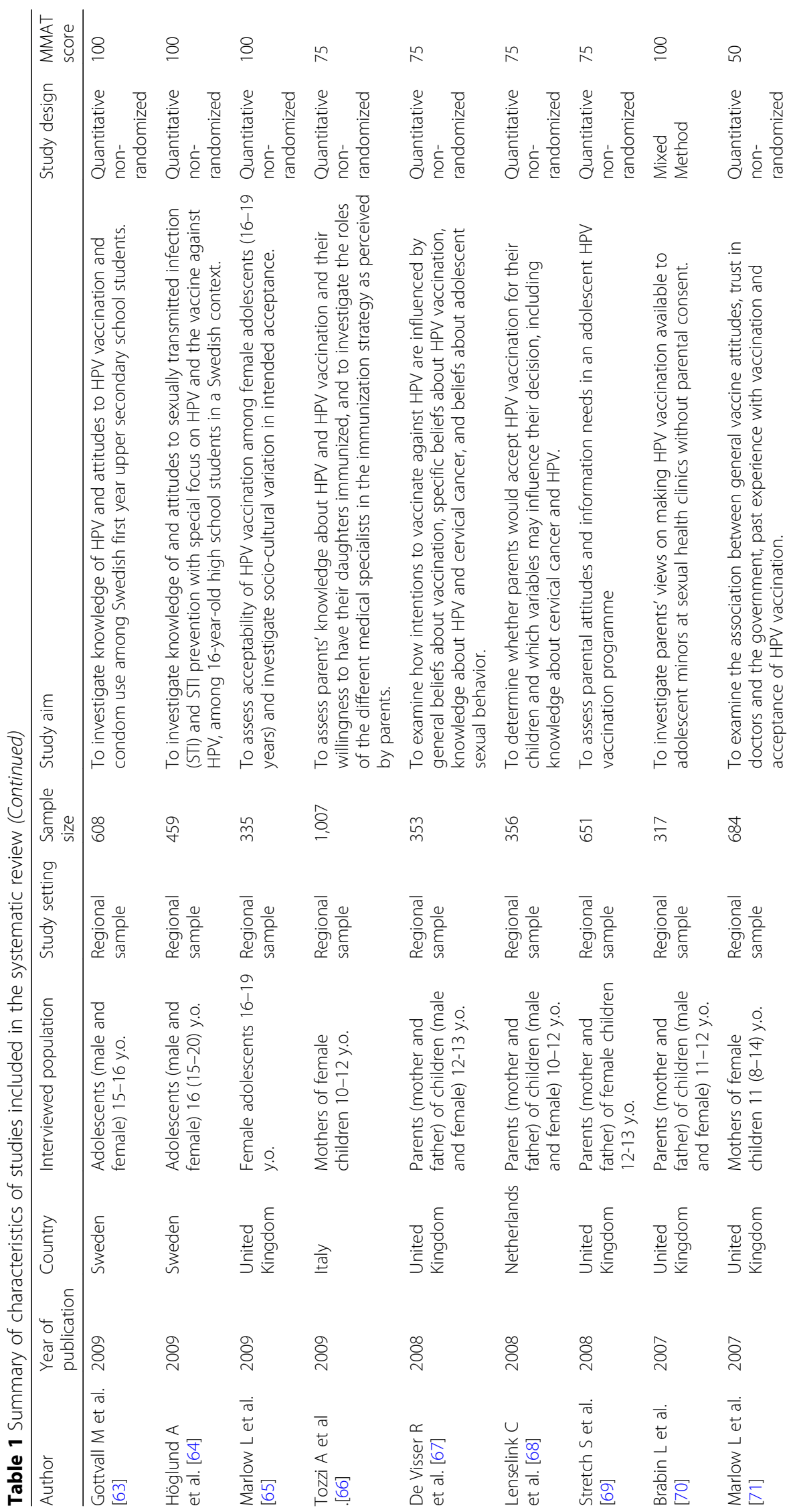




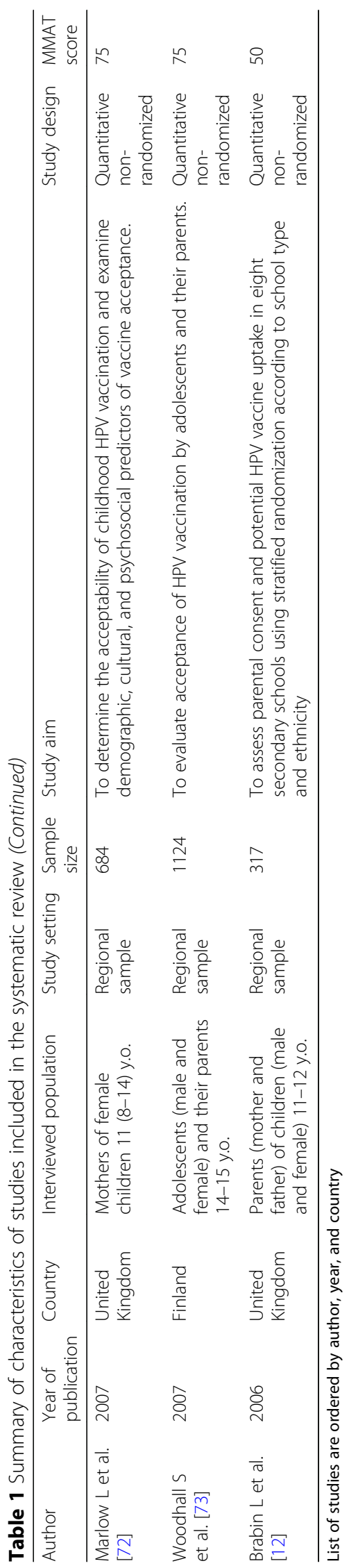




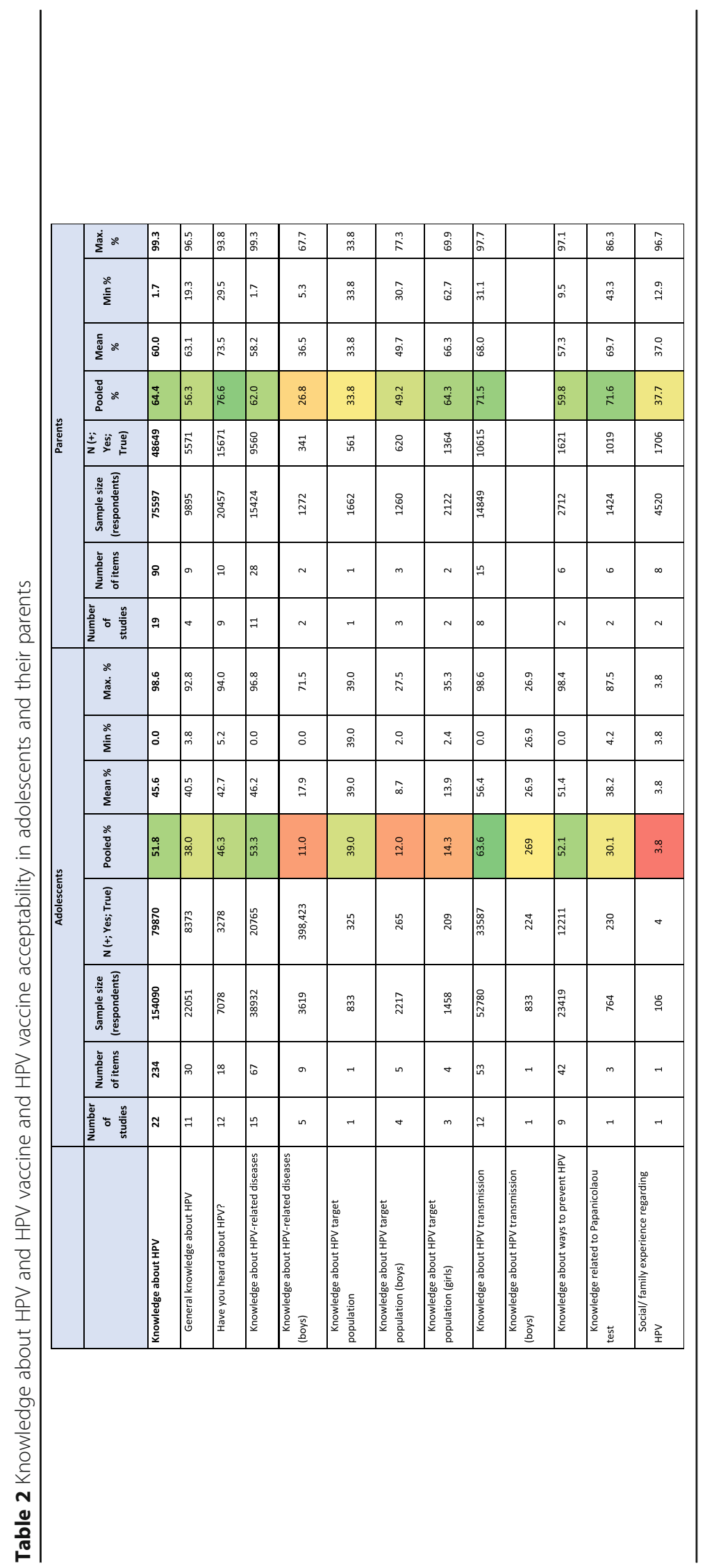




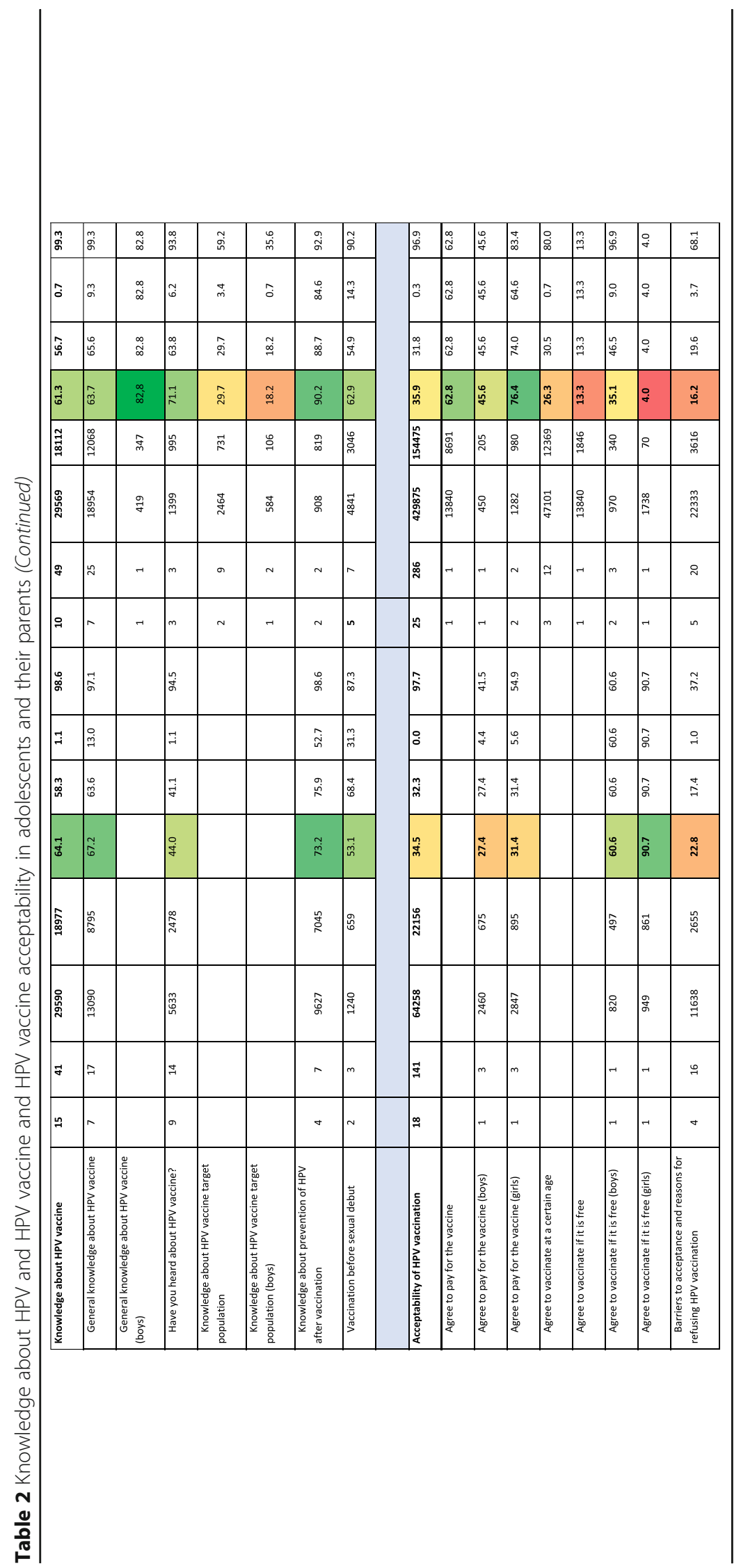




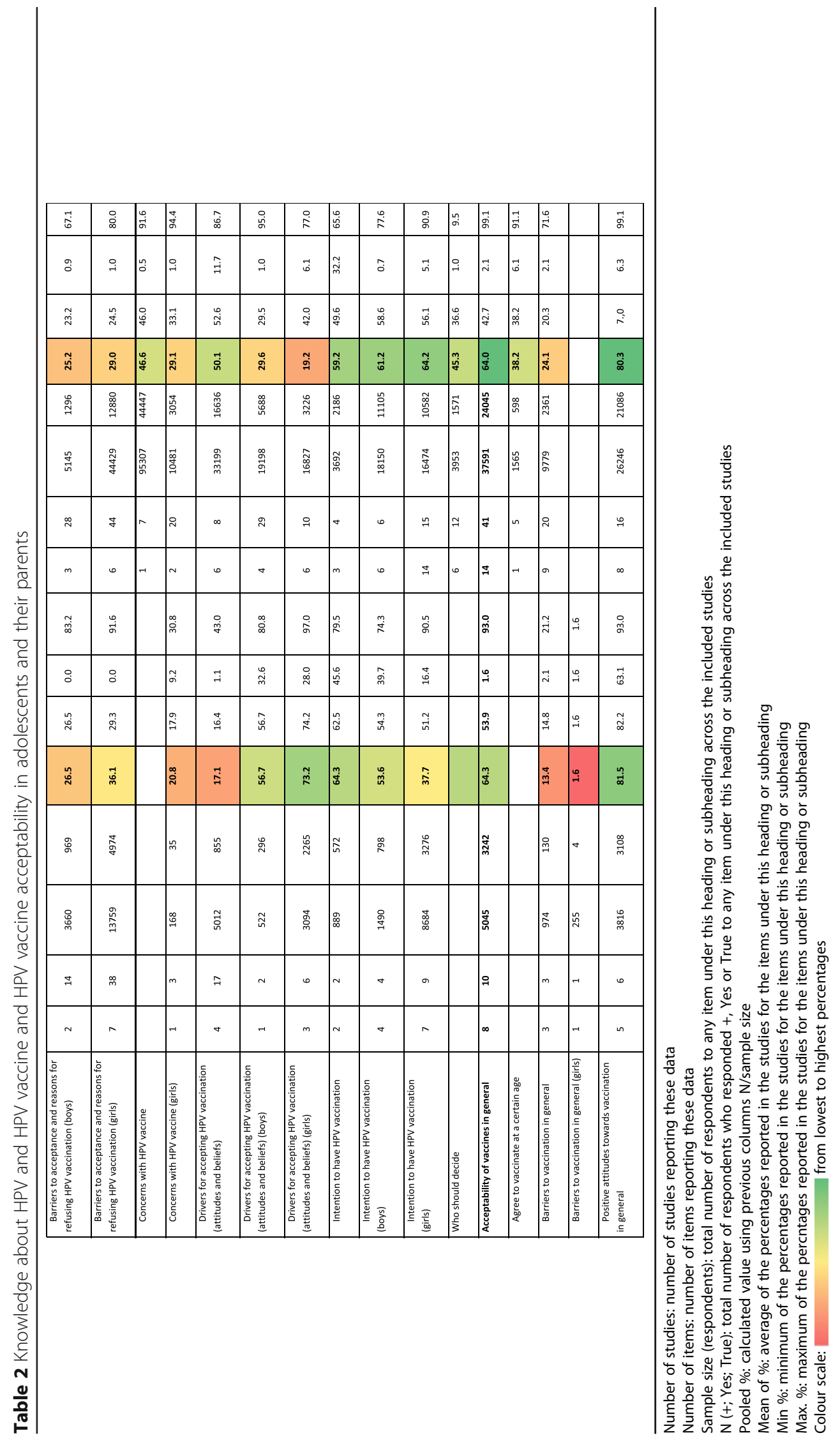




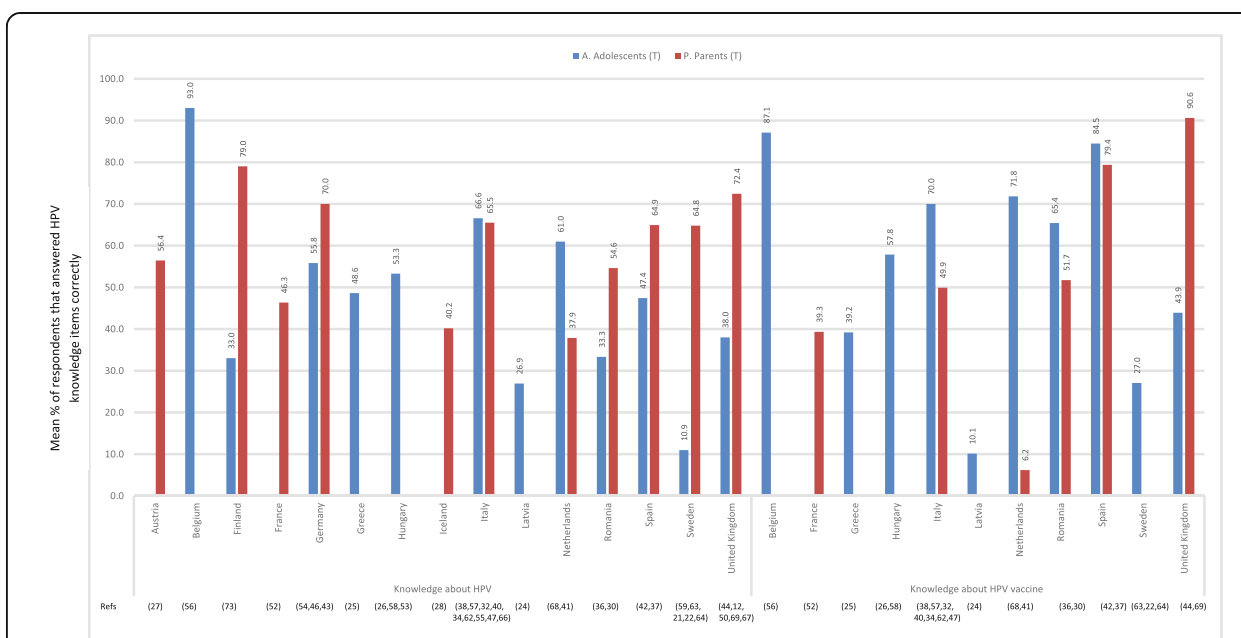

Fig. 2 Percentage of HPV and vaccine knowledge per country

[38], although this figure came from a single study, and for adolescents it was family doctor or medical staff ranging from 4.2\% [36] to 32\% [32] (See Supplementary Material).

There were some differences regarding knowledge related to gender. Only $12.0 \%$ (pooled percentage) (ranging from 2.0\% [63] to 27.5\% [44]) of adolescents knew that males are target for HPV infection versus a pooled percentage of $13.9 \%$ that knew females are target for HPV infection (ranging from 2.4\% [63] to $35.3 \%$ [22]).

\section{Results of studies evaluating HPV vaccine acceptance in adolescents and their parents}

Forty studies reported data on HPV vaccine acceptance. Table 2 presents the results of each study included in this systematic review grouped by headings and subheadings. Further, 64,258 adolescents and 429,875 parents answered at least one

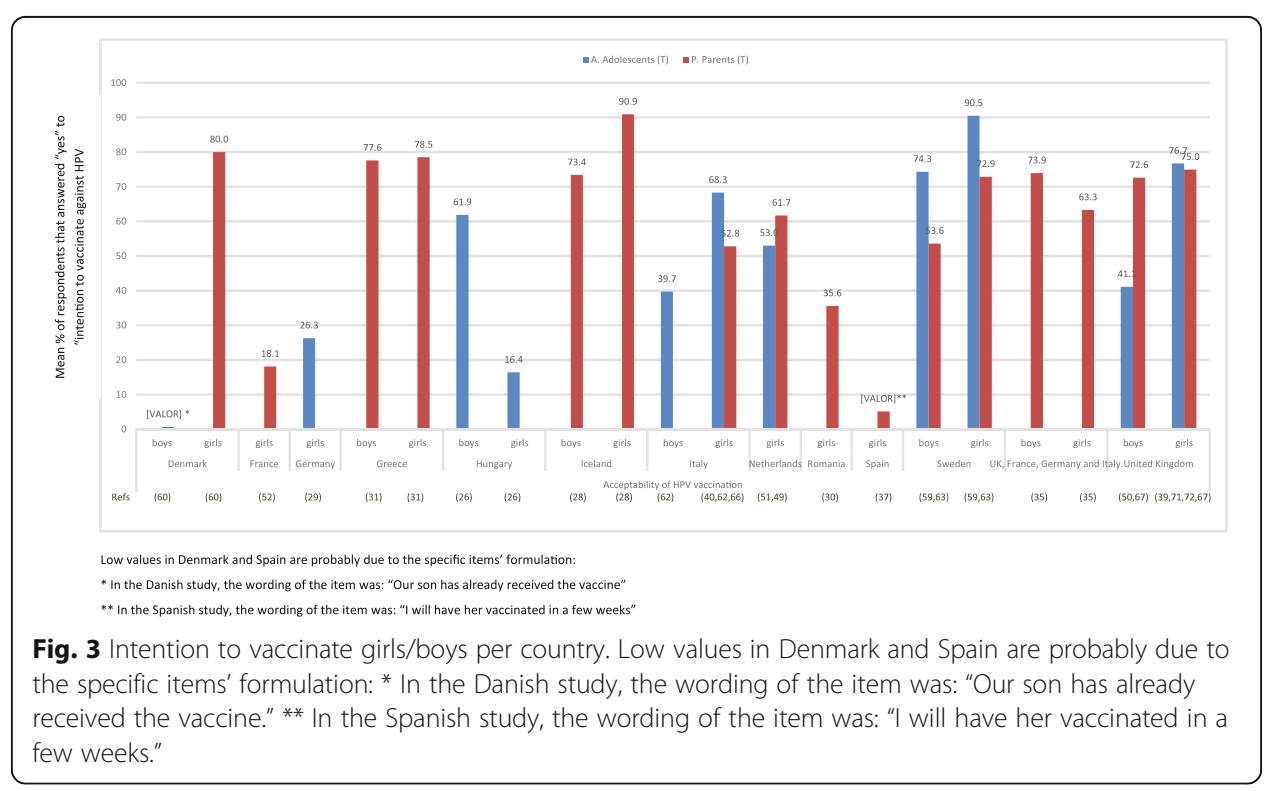


of the items on acceptance included in the studies included in this systematic review.

The percentage of adolescents with positive intention to be vaccinated against HPV was $64.3 \%$ (pooled percentage), ranging from $45.6 \%$ [73] to $79.5 \%$ [26]. Between $39.7 \%$ [62] and $74.3 \%$ [63] of adolescents showed positive attitude toward boys HPV vaccination.

The percentage of parents with positive intention to vaccinate their children against HPV was 59.2\% (pooled percentage) ranging from $32.2 \%$ [12] to $65.6 \%$ [62] and was quite similar in terms of vaccinating girls or boys.

By countries, studies conducted in Nordic countries like Sweden and Iceland presented the highest percentage of vaccine acceptance in adolescents and parents, respectively (Fig. 3).

Between 7.7\% [21] and 32.5\% [58] of adolescents, depending on the publication, had safety concerns about HPV vaccines, and 37\% in one study [73] considered that HPV vaccination may encourage early sexual debut. Regarding HPV vaccination in males, between $68.7 \%$ [36] and $83.2 \%$ [36] of adolescents reported lack of information as the major reason for refusing vaccination.

Among parents, between 7.9\% [71] and 68.1\%\% [30], depending on the publication, also reported safety concerns as the major barrier to refusing vaccination, followed by the idea that HPV vaccination may encourage sexual activity (10.5\% [59] to 42\% [73]). When questioned specifically about HPV vaccination in their sons, safety concerns (29.0\% [60] to 67.1\% [38]) and lack of information (25.5\% [35] to 56.5\% [35]) were also identified as the most common barriers.

In contrast, 7.7\% [22] to $43.0 \%$ [63] of adolescents and 13.7\% [59] to $73.4 \%$ [28] of parents considered the vaccine to be effective in protecting against HPV-related diseases. For HPV vaccination in males, 32.6\% [63] to 80.8\% [63] of adolescents and 17.9\% [38] to $91.9 \%$ [48] of parents also perceived the vaccine to be effective in males. Moreover, 26.2\% [35] to 84.6\% [35] of parents considered HPV vaccination of their sons as a social responsibility.

\section{Factors associated with HPV knowledge in adolescents and their parents}

The main sociodemographic factors associated with HPV knowledge in adolescents and their parents identified in this analysis were female gender (nine studies out of ten studying this factor), extent of higher education (five studies out of six), and higher income groups (one study out of two). Regardless of the investigators' questions about HPV knowledge, the percentage of female adolescents knowing about HPV is consistently higher than that of boys: ranging from $16.4 \%$ [63] to $92.8 \%$ [55] in adolescent females across the publications versus $8.1 \%$ [24] to 51.3\% [55] in adolescent males.

Adolescent's age at first sexual intercourse, age of respondent parents, and religion were also identified in several publications as being related with HPV knowledge, although results are discrepant.

Additionally, being vaccinated against HPV or having a vaccinated older sister were also positively associated with levels of HPV knowledge.

A complete list of factors associated with HPV knowledge is included in the Supplementary Material. 


\section{Factors associated with HPV vaccine acceptance}

Up to 80 factors presented a statistically significant association with HPV vaccine acceptance in at least one of the studies included in this systematic review: 21 were sociodemographic or family characteristics, 37 factors were drivers, and 22 were barriers to vaccine acceptance.

Within demographic factors, female gender and younger age of respondent parent, female gender of the adolescent, higher household income, and previous childhood vaccinations are the ones most consistently associated with HPV vaccine acceptance.

Drivers associated with HPV vaccine acceptance in the studies were belief in vaccine efficacy (eight studies out of eight studying this factor), existing awareness of HPV (six studies out of six), belief that HPV vaccine prevents cervical cancer (six studies out of six), susceptibility to HPV infection (four studies out of five), receiving information from the doctor (four studies out of four), desire to fit in social norms (four studies out of four), perception of disease severity (three studies out of three), and intention to do Pap test (three studies out of three).

The most frequently identified barriers to HPV vaccine acceptance were doubts about HPV vaccine safety profile (12 studies out of 12) followed by the belief that the vaccine will impact sexual behavior (six studies out of six), low perceived susceptibility to HPV infection (three studies out of three), and doubts about HPV vaccine efficacy (three studies out of three).

A complete summary of the factors associated with parental and adolescent HPV knowledge and vaccine acceptance is included in the Supplementary Material.

\section{Measurement tools used to evaluate HPV knowledge and vaccine acceptance in adolescents and their parents}

A complete list of items used in these questionnaires, including 38 and 40 questionnaires to assess HPV knowledge and vaccine acceptance respectively, is provided in the Supplementary Material.

\section{Discussion}

This review shows that HPV knowledge and vaccine acceptance vary widely across different studies and countries. In general, figures are still modest and lower in comparison with other routine vaccines. Safety concerns are still the main barrier to vaccination, and lack of HPV and vaccine knowledge has been identified, which is even greater for male vaccination. In contrast, main drivers to vaccination are perception of efficacy of HPV vaccine and social responsibility.

To our knowledge, this is the first systematic literature review to summarize factors influencing HPV knowledge and vaccine acceptance among adolescents and their parents since the marketing authorization of HPV vaccines in Europe and complementary to a recent systematic review on HPV vaccine hesitancy in Europe [75]. Additionally, it provides a compilation of the measurement tools, items, and questionnaires used in these published studies that can be useful for future research.

Vaccination acceptance is critical to ensuring the success of national immunization programs. Previous knowledge has been already identified as a known prerequisite for informed decision-making and vaccine acceptance [16]. HPV vaccination coverage rates 
and parental acceptance have been a subject of debate over the last decade, as they are still lower than expected in comparison with other vaccines administered routinely to adolescents. By May 2018, HPV immunization programs had been introduced in 80 countries, areas, or territories [76]. Although Scientific Societies and Public Health Authorities have made great efforts to guarantee the success of vaccination programs, there is still room for improvement, as vaccination coverage rate is still under $50 \%$ in many European countries [77]. For instance, Ireland and Denmark recently registered a decline in HPV vaccine uptake due to parental concerns. Cross-sectorial alliances between educational, parental, scientific, and political bodies were necessary to overcome this issue in those countries and ensure protection against morbidity and mortality associated to HPV related-cancer [78].

Recognition of the social and economic impact of the entire HPV burden of disease is still inadequate [1]: recurrent respiratory papillomatosis in children, highly contagious infections in adolescents, genital warts, precancerous lesions in young adults that may have consequences for reproductive capacity, and finally, a considerable number of cancers in different anatomic locations that affect males and females every year. The vast majority of this burden is attributable to HPV genotypes whose infection can be prevented with HPV vaccination. However, the population is not very aware of all this information [1] which is also reflected in our systematic review.

Our results show that HPV knowledge are still moderate and vary widely between European countries and the populations interviewed. These results are substantially aligned with findings from previous publications: according to Loke et al. [16], the percentage of adolescents that had heard about HPV infection and HPV vaccines varied between 21.5 and 77.6\% and 9.9 and 40.3\%, with Malaysia and Hong Kong being the countries with the highest percentage and Latvia the lowest. In parents, between 49.0\% (USA) and 92.7\% (Canada) had heard of HPV and between 43.7\% (Hong Kong) and 95\% (USA) about HPV vaccine. According to Radisic et al. [17], knowledge of HPV infection and vaccine in the male population was mostly modest, and parents often expressed a need for more information about HPV vaccine before taking decision about their sons' vaccination.

In our study, percentages of HPV vaccination acceptance are also quite modest and lower than for vaccines in general. The percentages of parents and adolescents that intended to vaccinate or receive the vaccination were $59.2 \%$ and $64.3 \%$, respectively.

As previously described, our results showed that female gender and having higher education impact HPV knowledge and vaccine acceptance positively. Main drivers for HPV vaccination included the perception of HPV severity and impact and the belief that HPV vaccines are effective. This was also identified in previous publications [20] and further work is required to increase HPV awareness in the population. The source of information is also known to be critical for a positive attitude-when information is provided by the doctor, a greater level of HPV knowledge and a vaccine acceptance were shown in parents and adolescents. A reliable source that provides balanced and understandable scientific information seems to be critical to making well-informed decisions. On the contrary, most common barriers were the idea that HPV vaccination may encourage sexual activity, and safety concerns.

More than 11 years after authorization, HPV vaccines have proven to be effective [79-83] and to have a favorable safety profile, as shown in clinical trials and post- 
authorization studies, in which a rapid reduction in HPV-related diseases has been observed following vaccine introduction $[84,85]$. This has been greatly acknowledged by major Health Bodies, such as the WHO [85], which in 2017 stated that accumulated safety studies including several million people showed no new adverse events of concern. More recently, the WHO has urged countries to set cervical cancer elimination goal and in other countries, such as the USA, Scientific Societies have even promoted HPV-cancer elimination goal, since HPV is responsible for a variety of cancers other than cervical cancer that affect both genders [86].

So far, 28 countries have extended their HPV national immunization programs to include boys and prevent them from suffering HPV-related diseases [76]. However, there is even less awareness of HPV infection in males and the fact that they can also benefit from HPV vaccination. According to our results, a small percentage of adolescents knew that males are targets of HPV infection, and only 5.3\% of mothers were aware about male diseases caused by HPV infection. Lack of information has also been identified in this and previous reviews as a key barrier to HPV vaccination in males [16]. Therefore, concerted efforts should be made to increase awareness of HPV infection in males and to ensure the success of HPV gender-neutral vaccination programs.

A recent review [87] has shown that informational strategies may influence the intent to vaccinate by increasing HPV-related knowledge and awareness, but the effect on $\mathrm{HPV}$ vaccine behavior is minimal. The most effective strategy to change vaccination behavior is multifaceted. This is consistent with a previous review [88] that also stressed the effectiveness of interventions that target both the provider and the patient.

Also, we found that HPV knowledge and vaccine acceptance varied by several patients' characteristics (in particular their socioeconomic background, as already found for other vaccines [89]). These results highlight the need for "tailored" interventions, carefully designed to respond to specific concerns and beliefs of the target population in order to reduce social inequalities in vaccination.

The items compiled in the different questionnaires could be useful for countries and investigators who intend to assess HPV knowledge and vaccine acceptance in their countries to make their results comparable with existing published data and to assess temporal trends or factors that influence the variations in HPV knowledge and vaccine acceptance.

Main limitations of this review stem from the variability across the studies included and, particularly from the lack of coincidence of the items used in each study to measure HPV knowledge and vaccine acceptance in adolescents and their parents. Also, it is difficult to assess a temporal trend in HPV knowledge and vaccine acceptance, as the questionnaires used and target populations differed widely between studies. Other limitations are heterogeneous sampling methods, sample sizes, population included, year of the study, and HPV vaccine implementation in the country. Also, this study is focused only in studies conducted in Europe and results cannot be extrapolated worldwide. This systematic review excluded all non-English-language publications. However, since most relevant research is commonly published in international journals in English, we do not expect to have missed any relevant study. Nevertheless, pooled results should be interpreted with caution.

\section{Conclusions}

Concerted efforts should be made to conduct multifaceted and tailored interventions to the population providing balanced information for decision-making on HPV 
vaccination. Increasing HPV vaccination uptake in males and females could dramatically change the epidemiology of HPV-related diseases and their consequences in countries.

\section{Supplementary information}

Supplementary information accompanies this paper at https://doi.org/10.1186/s40985-020-00126-5.

Additional file 1. SM-1- Search strategy.

\section{Abbreviations}

CIN: Cervical intraepithelial lesions; ECDC: European Centre for Disease Prevention and Control; EMA: European Medicines Agency; EU: European Union; HPV: Human Papillomavirus; MMAT: Mixed Method Assessment Tool; STI: Sexually transmitted infections; WHO: World Health Organization

\section{Acknowledgements}

Not applicable.

\section{Authors' contributions}

All authors contributed equally to this publication.

\section{Authors' information}

Not applicable.

\section{Funding}

This study was funded by Merck Sharp \& Dohme Spain.

\section{Availability of data and materials}

Not applicable.

\section{Ethics approval and consent to participate}

Not applicable.

\section{Consent for publication}

Not applicable.

\section{Competing interests}

NL, BR, and MC work for Merck Sharp \& Dohme Spain; MTA works for Adelphi Spain; MGS, and ISC report personal fees from Merck Sharp \& Dohme Spain during the study and personal fees from Merck Sharp \& Dohme Spain and GlaxoSmithKline outside the submitted work. MBP reports personal fees from Merck Sharp \& Dohme Spain during the study and personal fees from Merck Sharp \& Dohme Spain.

\section{Author details \\ ${ }^{1}$ Medical Affairs Department, Merck Sharp \& Dohme Spain, Madrid, Spain. ${ }^{2}$ Nazaret Healthcare Center, Valencia, Spain. ${ }^{3}$ Illescas Healthcare Center, Toledo, Spain. ${ }^{4}$ Instituto Hispalense de Pediatría, Sevilla, Spain. ${ }^{5}$ Adelphi Spain, Barcelona,} Spain.

Received: 19 March 2019 Accepted: 7 April 2020

Published online: 14 May 2020

\section{References}

1. Bosch FX, Broker TR, Forman D, Moscicki A, Gillison M, Doorbar J, et al. Comprehensive control of human papillomavirus infections and related diseases. Vaccine. 2013;31(Suppl 7):H1-31.

2. Hartwig S, St Guily JL, Dominiak-Felden G, Alemany L, de Sanjosé S. Estimation of the overall burden of cancers, precancerous lesions, and genital warts attributable to 9-valent HPV vaccine types in women and men in Europe. Infect Agent Cancer. 2017;12(1):19 Available from: http://infectagentscancer.biomedcentral.com/articles/10.1186/s13027-0170129-6.

3. Castellsagué X, Alemany L, Quer M, Halec G, Quirós B, Tous S, et al. HPV involvement in head and Neck Cancers: comprehensive assessment of biomarkers in 3680 patients. J Natl Cancer Inst. 2016;108(6):1-12.

4. Weaver BA. Epidemiology and natural history of genital human papillomavirus infection. J Am Osteopath Assoc. 2006; 106(3 Suppl 1):S2-8 Available from: http://www.ncbi.nlm.nih.gov/pubmed/16729554.

5. Chaturvedi AK, Anderson WF, Lortet-Tieulent J, Paula Curado M, Ferlay J, Franceschi S, et al. Worldwide trends in incidence rates for oral cavity and oropharyngeal cancers. J Clin Oncol. 2013;31(36):4550-9.

6. CHMP. GARDASIL, INN- human papillomavirus vaccine [Types 6,11,16,18] [ecombinant, adsorbed]. 2006.

7. CHMP. Cervarix, INN-human papilloma vaccine [KTypes 16,18] [Recombinant, adjuvant, adsorbed]. 2012

8. CHMP. GARDASIL 9. Agencia Eur Medicam. 2014.

9. Guidance E. Introduction of HPV vaccines in European Union countries—an update [Internet]. 2012. Available from: https://ecdc.europa.eu/sites/portal/files/media/en/publications/Publications/20120905_GUI_HPV_vaccine_update.pdf. 
10. Phillips M, Morais E, Kothan S, A T, Parellada C, Cashat M, et al. IPVC8-0348. Evolution of gender-neutral HPV vaccination in national immunization programs around the world. In: 32nd International Papillomavirus conference. Sydney; p. 545.

11. Dorleans F, Giambi C, Dematte L, Cotter S, Stefanoff P, Mereckiene J, et al. The current state of introduction of human papillomavirus vaccination into national immunisation schedules in Europe: first results of the VENICE2 2010 survey. Euro Surveill. 2010;15(47):1-4 Available from: http://www.ncbi.nlm.nih.gov/pubmed/21144444.

12. Brabin L, Roberts SA, Farzaneh F, Kitchener HC. Future acceptance of adolescent human papillomavirus vaccination: a survey of parental attitudes. Vaccine. 2006;24:3087-94.

13. Dubé E, Laberge C, Guay M, Bramadat P, Roy R, Julie A, et al. Vaccine hesitancy: an overview. 2013;5515.

14. Sekhon M, Cartwright M, Francis JJ. Acceptability of healthcare interventions : an overview of reviews and development of a theoretical framework. BMC Health Serv Res. 2017:1-13 Available from: https://doi.org/10.1186/s12913-017-2031-8.

15. Betsch C, Schmid P, Korn L, Steinmeyer L, Heinemeier D, Eitze S, et al. Impfverhalten psychologisch erklären , messen und verändern. 2019;

16. Loke AY, Kwan ML, Wong Y-T, AKY W. The uptake of human papillomavirus vaccination and its associated factors among adolescents: a systematic review. J Prim Care Community Health. 2017:1-14.

17. Radisic G, Chapman J, Flight I, Wilson C. Factors associated with parents' attitudes to the HPV vaccination of their adolescent sons: A systematic review. Prev Med. 2017;95:26-37.

18. Pluye $P$, Robert $E$, Cargo M, Bartlett $G$. Proposal: a mixed methods appraisal tool for systematic mixed studies reviews. Montréal McGill Univ. 2011;(Part I):1-8. Available from: http://mixedmethodsappraisaltoolpublic.pbworks.com/w/file/843 71689/MMAT 2011 criteria and tutorial 2011-06-29updated2014.08.21.pdf.

19. Alberts CJ, van der Loeff MFS, Hazeveld Y, de Melker HE, van der Wal MF, Nielen A, et al. A longitudinal study on determinants of HPV vaccination uptake in parents/guardians from different ethnic backgrounds in Amsterdam, the Netherlands. BMC Public Health. 2017;17(1):220 Available from: http://bmcpublichealth.biomedcentral.com/articles/10.11 86/s12889-017-4091-4.

20. Anagnostou PA, Aletras VH, Niakas DA. Human papillomavirus knowledge and vaccine acceptability among adolescents in a Greek region. Public Health. 2017;152:145-52 Available from: https://doi.org/10.1016/j.puhe.2017.07.033.

21. Grandahl M, Tydén T, Westerling R, Nevéus T, Rosenblad A, Hedin E, et al. To consent or decline HPV vaccination: a pilot study at the start of the national school-based vaccination program in Sweden. J Sch Health. 2017:87(1):62-70.

22. Grandahl M, Larsson M, Dalianis T, Stenhammar C, Tydén T, Westerling R, et al. Catch-up HPV vaccination status of adolescents in relation to socioeconomic factors, individual beliefs and sexual behaviour. PLoS One. 2017;12(11):1-16.

23. Navarro-lllana P, Navarro-Illana E, Vila-Candel R, Díez-Domingo J. Drivers for human papillomavirus vaccination in Valencia (Spain). Gaceta Sanitaria. 2017.

24. Patel H, Pčolkina K, Strazdina K, Viberga I, Sherman SM, Tincello DG, et al. Awareness of HPV infection and attitudes toward HPV vaccination among Latvian adolescents. Int J Gynecol Obstet. 2017;137(2):138-44.

25. Vaidakis D, Moustaki I, Zervas I, Barbouni A, Merakou K, Chrysi MS, et al. Knowledge of Greek adolescents on human papilloma virus (HPV) and vaccination: A national epidemiologic study. Medicine (Baltimore). 2017;96(1):e5287.

26. Balla B, Terebessy A, Tóth E, Balázs P. Young Hungarian Students' Knowledge about HPV and their attitude toward hpv vaccination. Vaccines. 2016;5(1):1 Available from: http://www.mdpi.com/2076-393X/5/1/1.

27. Borena W, Luckner-Hornischer A, Katzgraber F, Holm-von LD. Factors affecting HPV vaccine acceptance in west Austria: do we need to revise the current immunization scheme? Papillomavirus Res. 2016;2(June):173-7 Available from https:// doi.org/10.1016/j.pvr.2016.10.001.

28. Oddsson K, Gudmundsdottir T, Briem H. Attitudes and knowledge among parents or guardians of 12-year-old girls about HPV vaccination - a population-based survey in Iceland. Eur J Gynaecol Oncol. 2016.

29. Schülein S, Taylor KJ, König J, Claus M, Blettner M, Klug SJ. Factors influencing uptake of HPV vaccination among girls in Germany. BMC Public Health. 2016;16(1):1-8 Available from: https://doi.org/10.1186/s12889-016-3663-z.

30. Voidazan S, Tarcea M, Morariu S-H, Grigore A, Dobreanu M. Human papillomavirus vaccine-knowledge and attitudes among parents of children aged 10-14 years: a cross-sectional study, Tirgu Mures, Romania. Cent Eur J Public Health. 2016;24(1):29-38.

31. Agorastos T, Chatzistamatiou K, Zafrakas M, Siamanta V, Katsamagkas T, Constantinidis T, et al. Distinct demographic factors influence the acceptance of vaccination against HPV. Arch Gynecol Obstet. 2015;292(1):197-205.

32. Firenze A, Marsala MGL, Bonanno V, Maranto M, Ferrara C, Giovannelli L, et al. Facilitators and barriers HPV unvaccinated girls after 5 years of program implementation. Hum Vaccines Immunother. 2015;11(1):240-4.

33. Forster AS, Waller J, Bowyer HL, Marlow LAV. Girls' explanations for being unvaccinated or under vaccinated against human papillomavirus: a content analysis of survey responses. BMC Public Health. 2015;15(1):6-13 Available from: https://doi.org/10.1186/s12889-015-2657-6.

34. La Torre G, De Vito E, Ficarra MG, Firenze A, Gregorio P, Miccoli S, et al. Knowledge, opinions and attitudes of Italian mothers towards HPV vaccination and Pap test. Tumori. 2015;101(3):339-46.

35. Lee Mortensen G, Adam M, Idtaleb L. Parental attitudes towards male human papillomavirus vaccination: a panEuropean cross-sectional survey. BMC Public Health. 2015;15(1):624 Available from: http://bmcpublichealth. biomedcentral.com/articles/10.1186/s12889-015-1863-6.

36. Maier C, Maier T, Neagu CE, Vlədəreanu R. Romanian adolescents' knowledge and attitudes towards human papillomavirus infection and prophylactic vaccination. Eur J Obstet Gynecol Reprod Biol. 2015;195:77-82.

37. Navarro-Illana P, Caballero P, Tuells J, Puig-Barberá J, Diez-Domingo J. Acceptability of human papillomavirus vaccine in mothers from Valencia (Spain). An Pediatr (Barc). 2015;83(5):318-27 Available from: http://www.analesdepediatria.org/es/ aceptabilidad-vacuna-contra-el-virus/articulo/S169540331400558X/.

38. Bianco A, Pileggi C, lozzo F, Nobile CGA, Pavia M. Vaccination against human papilloma virus infection in male adolescents: knowledge, attitudes, and acceptability among parents in Italy. Hum Vaccin Immunother. 2014;10(9):2536-42.

39. Bowyer HL, Forster AS, LAV M, Waller J. Predicting human papillomavirus vaccination behaviour among adolescent girls in England: results from a prospective survey. J Fam Plan Reprod Heal Care. 2014;40(1):14-22 Available from: http:// jfprhc.bmj.com/lookup/doi/10.1136/jpprhc-2013-100583.

40. Giambi C, D'Ancona F, Del Manso M, De Mei B, Giovannelli I, Cattaneo C, et al. Exploring reasons for non-vaccination against human papillomavirus in Italy. BMC Infect Dis. 2014;14(1):1-9. 
41. Mollers M, Lubbers K, Spoelstra SK, Weijmar-Schultz WCM, Daemen T, Westra TA, et al. Equity in human papilloma virus vaccination uptake?: Sexual behaviour, knowledge and demographics in a cross-sectional study in (un)vaccinated girls in the Netherlands. BMC Public Health. 2014;14(1):1-11 Available from: BMC Public Health.

42. Navarro-lllana P, Diez-Domingo J, Navarro-lllana E, Tuells J, Alemán S, Puig-Barberá J. Knowledge and attitudes of Spanish adolescent girls towards human papillomavirus infection: Where to intervene to improve vaccination coverage. BMC Public Health. 2014;14(1):1-8.

43. Wegwarth O, Kurzenhäuser-Carstens S, Gigerenzer G. Overcoming the knowledge-behavior gap: the effect of evidencebased HPV vaccination leaflets on understanding, intention, and actual vaccination decision. Vaccine. 2014;32(12):138893 Available from https://doi.org/10.1016/j.vaccine.2013.12.038.

44. Bowyer HL, Marlow LAV, Hibbitts S, Pollock KG, Waller J. Knowledge and awareness of HPV and the HPV vaccine among young women in the first routinely vaccinated cohort in England. Vaccine. 2013;31(7):1051-6 Available from: https://doi. org/10.1016/j.vaccine.2012.12.038

45. Hofman R, Schiffers PA, Richardus JH, Raat H, De Kok IM, Van Ballegooijen M, et al. Increasing girls' knowledge about human papillomavirus vaccination with a pre-test and a national leaflet: a quasi-experimental study. BMC Public Health. 2013;13(1):1 Available from: BMC Public Health.

46. Stöcker P, Dehnert M, Schuster M, Wichmann O, Deleré Y. Human papillomavirus vaccine uptake, knowledge and attitude among 10th grade students in Berlin, Germany, 2010. Hum Vaccin Immunother. 2013;9(1):74-82 Available from: http://search.ebscohost.com/login.aspx?direct=true\&db=cmedm\&AN=22995838\&site=ehost-live\&scope=cite.

47. Sopracordevole F, Cigolot F, Mancioli F, Agarossi A, Boselli F, Ciavattini A. Knowledge of HPV infection and vaccination among vaccinated and unvaccinated teenaged girls. Int J Gynecol Obstet. 2013;122(1):48-51.

48. Tisi G, Salinaro F, Apostoli P, Bassani R, Bellicini A, Groppi L, et al. HPV vaccination acceptability in young boys. Ann Ist Super Sanita. 2013.

49. Van Keulen HM, Otten W, Ruiter RAC, Fekkes M, Van Steenbergen J, Dusseldorp E, et al. Determinants of HPV vaccination intentions among Dutch girls and their mothers: A cross-sectional study. BMC Public Health. 2013;13(1):1 Available from: BMC Public Health.

50. Forster AS, Marlow LAV, Wardle J, Stephenson J, Waller J. Interest in having HPV vaccination among adolescent boys in England. Vaccine. 2012;30(30):4505-10 Available from: https://doi.org/10.1016/j.vaccine.2012.04.066.

51. Gefenaite G, Smit M, Nijman HW, Tami A, Drijfhout IH, Pascal A, et al. Comparatively low attendance during Human Papillomavirus catch-up vaccination among teenage girls in the Netherlands: Insights from a behavioral survey among parents. BMC Public Health. 2012;12(1):1 Available from: ???

52. Haesebaert J, Lutringer-Magnin D, Kalecinski J, Barone G, Jacquard A-C, Régnier V, et al. French women's knowledge of and attitudes towards cervical cancer prevention and the acceptability of HPV vaccination among those with 14-18 year old daughters: a quantitative-qualitative study. BMC Public Health. 2012;12(1):1034 Available from: http:// bmcpublichealth.biomedcentral.com/articles/10.1186/1471-2458-12-1034.

53. Marek E, Dergez T, Rebek-Nagy G, Szilard I, Kiss I, Ember I, et al. Effect of an educational intervention on Hungarian adolescents' awareness, beliefs and attitudes on the prevention of cervical cancer. Vaccine. 2012;30(48):6824-32 Available from: https://doi.org/10.1016/i.vaccine.2012.09.012.

54. Samkange-Zeeb F, Spallek L, Klug SJ, Zeeb H. HPV infection awareness and self-reported HPV vaccination coverage in female adolescent students in two German cities. J Community Health. 2012;37(6):1151-6.

55. Sopracordevole F, Cigolot F, Gardonio V, Boselli F, Di Giuseppe J, Ciavattini A. Teenagers' knowledge about HPV infection and HPV vaccination in the first year of the public vaccination programme. Eur J Clin Microbiol Infect Dis. 2012;31(9):2319-25.

56. Balemans R, Devroey D, Van De Vijver E, Chovanova H, Vandevoorde J. Knowledge and attitudes about vaccinations among adolescents. J Prev Med Hyg. 2011;52(2):64-72.

57. Chadenier GMC, Colzani E, Faccini M, Borriello CR, Bonazzi C. Assessment of the first HPV vaccination campaign in two northern Italian health districts. Vaccine. 2011;29(26):4405-8 Available from: https://doi.org/10.1016/j.vaccine.2011.04.007.

58. Marek E, Dergez T, Rebek-Nagy G, Kricskovics A, Kovacs K, Bozsa S, et al. Adolescents' awareness of HPV infections and attitudes towards HPV vaccination 3 years following the introduction of the HPV vaccine in Hungary. Vaccine. 2011; 29(47):8591-8 Available from: https://doi.org/10.1016/j.vaccine.2011.09.018.

59. Dahlström LA, Tran TN, Lundholm C, Young C, Sundström K, Sparén P. Attitudes to HPV vaccination among parents of children aged 12-15 years - A population-based survey in Sweden. Int J Cancer. 2010;126(2):500-7.

60. Mortensen GL. Parental attitudes towards vaccinating sons with human papillomavirus vaccine. Dan Med Bull. 2010; 57(12):A4230.

61. Morison LA, Cozzolino PJ, Orbell S. Temporal perspective and parental intention to accept the human papillomavirus vaccination for their daughter. Br J Health Psychol. 2010;15(1):151-65.

62. Pelucchi C, Esposito S, Galeone C, Semino M, Sabatini C, Picciolli I, et al. Knowledge of human papillomavirus infection and its prevention among adolescents and parents in the greater Milan area, Northern Italy. BMC Public Health. 2010;10.

63. Gottvall M, Larsson M, Höglund AT, Tydén T. High HPV vaccine acceptance despite low awareness among Swedish upper secondary school students HPV and upper secondary school students Gottvall et al. Eur I Contracept Reprod Heal Care. 2009;14(6):399-405.

64. Hoglund AT, Tyden T, Hannerfors T, Larsson M. Knowledge of HPV and attitudes to HPV vaccination among Swedish high school students. Eur J Contracept Reprod Heal Care. 2010;15:53.

65. Marlow LAV, Waller J, Evans REC, Wardle J. Predictors of interest in HPV vaccination: a study of British adolescents. Vaccine. 2009;27(18):2483-8.

66. Tozzi AE, Ravà L, Stat D, Pandolfi E, Marino MG, Ugazio AG. Attitudes towards HPV immunization of Italian mothers of adolescent girls and potential role of health professionals in the immunization program. Vaccine. 2009;27(19):2625-9.

67. de Visser R, Mc Donnell E. Corelates of parents' reports of acceptability of human papilloma virus vaccination for their school-aged children. Sex Health. 2008:5:331-8.

68. Lenselink CH, Gerrits MMJG, Melchers WJG, Massuger LFAG, van Hamont D, Bekkers RLM. Parental acceptance of Human Papillomavirus vaccines. Eur J Obstet Gynecol Reprod Biol. 2008;137(1):103-7.

69. Stretch R, Roberts SA, McCann R, Baxter D, Chambers G, Kitchener $H$, et al. Parental attitudes and information needs in an adolescent HPV vaccination programme. Br J Cancer. 2008;99(11):1908-11. 
70. Brabin L, Roberts SA, Kitchener HC. A semi-qualitative study of attitudes to vaccinating adolescents against human papillomavirus without parental consent. BMC Public Health. 2007;7:1-7.

71. Marlow LAV, Waller J, Wardle J. Trust and experience as predictors of HPV vaccine acceptance. Hum Vaccin. 2007;3(5):171-5.

72. Marlow LAV, Waller J, Wardle J. Parental attitudes to pre-pubertal HPV vaccination. Vaccine. 2007;25(11):1945-52.

73. Woodhall SC, Lehtinen M, Verho T, Huhtala H, Hokkanen M, Kosunen E. Anticipated acceptance of HPV vaccination at the baseline of implementation: a survey of parental and adolescent knowledge and attitudes in Finland. J Adolesc Heal. 2007;40(5):466-9.

74. Navarro-lllana P, Caballero P, Tuells J, Puig-Barberá J, Diez-Domingo J. Aceptabilidad de la vacuna contra el virus del papiloma humano en madres de la provincia de Valencia (España). An Pediatr. 2015;83(5):318-27 Available from: https:// doi.org/10.1016/j.anpedi.2014.11.018.

75. Karafillakis E, Simas C, Jarrett C, Verger P, Peretti-Watel P, Dib F, et al. HPV vaccination in a context of public mistrust and uncertainty: a systematic literature review of determinants of HPV vaccine hesitancy in Europe. Hum Vaccines Immunother. 2019;15(7-8):1615-27 Available from: https://doi.org/10.1080/21645515.2018.1564436.

76. Vorsters A, Van Damme P. HPV immunization programs: ensuring their sustainability and resilience. Vaccine. 2018:1016-8.

77. Eurosurveillance editorial team. Updated version of ECDC Guidance on human papillomavirus vaccines in Europe available. Euro Surveill Bull Eur sur les Mal Transm Eur Commun Dis Bull. 2012;17(37):20120905.

78. Corcoran B, Clarke A, Barrett T. Rapid response to HPV vaccination crisis in Ireland. Lancet. 2018:391(10135):2103.

79. Szarewski A, Skinner SR, Garland SM, Romanowski B, Schwarz TF, Apter D, et al. Efficacy of the HPV-16/18 AS04adjuvanted vaccine against low-risk HPV types (PATRICIA Randomized Trial): an unexpected observation. J Infect Dis. 2013;208(9):1391-6.

80. Joura EA, Leodolter $\mathrm{S}$, Hernandez-avila M, Wheeler CM, Perez G, Koutsky LA, et al. Efficacy of a quadrivalent prophylactic human vaccine against high-grade vulval and vaginal lesions : a combined analysis of three randomised clinical trials. 2000;1693-1702.

81. Schiller JT, Castellsagué X, Garland SM. A review of clinical trials of human papillomavirus prophylactic vaccines. Vaccine. 2012;30(SUPPL.5):F123-38

82. Garland SM, Kjaer SK, Muñoz N, Block SL, Brown DR, Dinubile MJ, et al. Impact and effectiveness of the quadrivalent human papillomavirus vaccine: a systematic review of 10 years of real-world experience. Clin Infect Dis. 2016;63:519-27.

83. Moreira EDJ, Block SL, Ferris D, Giuliano AR, Iversen O-E, Joura EA, et al. Safety profile of the 9-valent HPV vaccine: A combined analysis of 7 phase III clinical trials. Pediatrics. 2016;138(2).

84. Stillo M, Carrillo Santisteve P, Lopalco PL. Safety of human papillomavirus vaccines: a review. Expert Opin Drug Saf. 2015: 14(5):697-712.

85. World Health Organization. Global Advisory Committee on Vaccine safety Statement on Safety of HPV vaccines. World Heal Organ. 2015;(December):3-5.

86. NCl-Cancer Centers HPV elimination consensusstatement_Posted 06.

87. Rodriguez AM, Do TQN, Goodman M, Schmeler KM, Kaul S, Kuo Y. Human Papillomavirus Vaccine Interventions in the Am J Prev Med. 2018;000(000):1-12 Available from: https://doi.org/10.1016/j.amepre.2018.10.033.

88. Walling EB, Benzoni N, Dornfeld J, Bhandari R. Interventions to Improve HPV Vaccine Uptake : A Systematic Review. 2016;138(1):1-13.

89. Bocquier A, Ward J, Raude J, Peretti-watel P. Socioeconomic differences in childhood vaccination in developed countries : a systematic review of quantitative studies. 2017;0584(September).

\section{Publisher's Note}

Springer Nature remains neutral with regard to jurisdictional claims in published maps and institutional affiliations.

Ready to submit your research? Choose BMC and benefit from:
- fast, convenient online submission
- thorough peer review by experienced researchers in your field
- rapid publication on acceptance
- support for research data, including large and complex data types
- gold Open Access which fosters wider collaboration and increased citations
- maximum visibility for your research: over 100M website views per year
At BMC, research is always in progress.
Learn more biomedcentral.com/submissions

